MARIANO LAMBEA

\title{
TEORÍA Y PRÁCTICA DEL COMPASILLO Y DE LA PROPORCIÓN MENOR
}

\author{
Separata de la \\ REVISTA DE MUSICOLOGÍA \\ Volumen XXII, $\mathrm{n}^{\circ} 1$ \\ Junio de 1999
}

MADRID

1999 


\section{TEORÍA Y PRÁCTICA DEL COMPASILLO Y DE LA PROPORCIÓN MENOR}

Resumen: Se estudia la importancia que merecen las referencias sobre estos compases, tanto en su configuración teórica como en su aplicación práctica, contenidas en los tratados teóricos de tratadistas tan importantes e influyentes como Bermudo, Cerone, Lorente y Nassarre. El uso mayoritario de estos compases en la música española desde finales del siglo XVI hasta principios del XVIII, en obras con texto en lengua vulgar, como villancicos y romances religiosos y profanos, hace necesario su estudio detenido, que conviene diversificar en dos vertientes: por una parte, la teórica, preferentemente de carácter musicológico, y, por otra, la práctica, especialmente de carácter interpretativo. A partir de los contenidos de este artículo, esta última vertiente pretende tener su ámbito de aplicación en la interpretación de la música antigua española siguiendo criterios históricos y musicológicos.

\section{THEORY AND PARCTICE OF THE "COMPASILLO" AND THE "ProporCiÓN MENOR"}

Summary: This article studies the attention deserved by these compasses, both from the theoretical and from the practical points of view, in treatises of such important and influential theorists as Bermudo, Cerone, Lorente and Nasarre. Their detailed analysis is relevant since they are the most widely used compasses in the Spanish music of the late XVIth century and the early XVIIth century in works in vernacular, such as the villancicos and the romances, both religous and profane. Two different approaches seem to be necessary: the theoretical point of view of the musicologist, and the practical point of view of the player. Regarding this practical side, this article intends to provide historical and musicological information for players of Spanish Ancient Music.

\section{INTRODUCCIÓN}

La finalidad del presente artículo obedece a un doble propósito claramente especificado en su título: por una parte, la explanación teórica de ambos com- 
pases, y, por otra, su aplicación práctica ${ }^{1}$. Ambos aspectos, teóricos y prácticos, han sido entresacados de tratadistas de la música tan importantes e influyentes como Fray Juan Bermudo ( ${ }^{*}$ c.1510 - tc.1565), Pedro Cerone ( ${ }^{*} 1566$ - †1625), Andrés Lorente $\left({ }^{*} 1624-+1703\right)$ y Fray Pablo Nassarre $\left({ }^{*} c .1664-+1730\right)$.

En los tiempos que corren, son cada vez más los intérpretes de música antigua que optan por una interpretación basada en criterios históricos y que exigen, tanto la utilización de la fuente original, como, en su defecto, la transcripción lo más filológica y científica posible, y, por consiguiente, próxima a la grafía original, a la cual debe la máxima fidelidad. Los criterios historicistas de interpretación no sólo se basan en la recuperación de instrumentos y voces originales y respeto a las grafías musicales, sino que se refieren también al seguimiento de la teoría musical de la época, leída y entendida con buen sentido. Todos estos criterios tienen como único objetivo recuperar la realidad sonora que subyace oculta en las fuentes musicales antiguas, ofreciendo una interpretación musical rigurosa, fidedigna y acorde con la mentalidad y el sentimiento con que fueron escritas esas músicas, posibilitando así el placer estético y cultural que hoy nos proporciona su audición.

Volviendo al doble propósito del artículo, también me gustaría que su contenido fuera útil tanto a músicos teóricos, como a los prácticos. Es probable que lo que sigue a continuación sea de sobra conocido por ambas facciones de la gran familia musicológica, pero para aquellos que se inician en la música antigua o para quienes no hayan tenido tiempo -o humor- de hurgar en la teoría, e incluso para los musicólogos noveles que se enfrentan a sus primeras transcripciones, modestamente les ofrezco aquí, condensados, los pensamientos de algunos de nuestros tratadistas que yo, con más paciencia que fortuna, he ido recogiendo y disponiendo. Por otra parte, he querido que el trabajo tenga cierto carácter didáctico y por eso he incluido ejemplos musicales extraídos tanto de los propios tratadistas como de manuscritos a los que he tenido acceso, y de los cuales no es necesario citar su procedencia, puesto que los fragmentos reproducidos son muy breves y existen por centenares en todas las fuentes musicales de esta época.

Asímismo quiero resaltar que, a partir de este trabajo, confío en poder estudiar y analizar con mayor precisión las relaciones entre texto musical y texto poético en romances y villancicos del siglo $\mathrm{XVII}^{2}$, tanto religiosos como pro-

\footnotetext{
'Sobre este tema vid. el excelente trabajo de Luis ROBLEDO: Juan Blas de Castro (ca. 1561-1631). Vida y obra musical, Zaragoza, Institución Fernando el Católico, 1989, pp. 94b-98b.

${ }^{2}$ Vid. en este sentido los imprescindibles trabajos del Prof. José Vicente GONZÁLEZ VALLE: "Relación música y lenguaje en los teóricos españoles de música de los siglos XVI y XVII", en Anuario Musical, 43 (1988), pp. 95-109. •"Relación música/texto en la composición musical en castellano del s. XVII. Nueva estructura rítmica de la música española", en Anuario Musical, 47 (1992), pp. 103-132. •"La nota-
} 
fanos, que, como se sabe, presentan un uso masivo del compasillo y la proporción, ya sea por separado en cada pieza o conjuntamente en una misma composición.

En síntesis, mi principal motivación ha sido servir a la mejor interpretación de nuestra música antigua, que la tenemos — en gran cantidad y calidad — desperdigada por todo el país, en espera de ser conocida, difundida y apreciada.

\section{EL COMPÁS MENOR, TIEMPO MENOR IMPERFECTO, COMPASILLO O COMPASETE: $\mathrm{C}$}

\section{Aspectos teóricos}

No es este el lugar adecuado para repasar por extenso el amplio corpus de la teoría musical española, en lo que se refiere al tema de la aparición de este compás y a sus cambios de significado. Una síntesis bien expuesta sobre esta materia se encuentra en el compendio de León Tello, ${ }^{3}$ donde se pasa revista a numerosos tratadistas musicales - anteriores a las primeras décadas del siglo XVII- y a sus diversas aportaciones, agrupadas bajo distintos epígrafes. Por mi parte, intentaré extraer los aspectos que considero más importantes sobre este tema, de la mano de teóricos musicales suficientemente reconocidos. ${ }^{4}$

El compás C tal como lo conocemos hoy se encuentra codificado y sistematizado a partir de los escritos de Fray Juan Bermudo. Según León Tello, este teórico consigue desvincular el compás $C$ de toda la carga mensuralista mantenida por los tratadistas inmediatamente anteriores a él, y caída ahora en desuso. Bermudo define así el concepto de compás en general:

ción de la música vocal española del s. XVII. Cambio y significado según la teoría y práctica musicales de la época", en ALTES IM NEUEN: Fetschrift Theodor Göllner, Herausgegeben von Bernd EDELMANN und Manfred HERMANN SCHMID, Tutzing, 1995, pp. 177-191. •"Relación entre el verso castellano y la técnica de composición musical en los villancicos de Fr. Manuel Correa (s. XVII)", en Anuario Musical, 51 (1996), pp. 39-69.

${ }^{3}$ Francisco José LEÓN TELLO: Estudios de Historia de la Teoría Musical, Madrid, Consejo Superior de Investigaciones Científicas, 1991 ( $2^{\mathrm{a}}$ ed.), (Colección Textos Universitarios, $\left.\mathrm{n}^{\circ} 14\right)$. Vid. especialmente el "Capítulo III. Teoría del canto polifónico", pp. 469-537.

${ }^{4}$ Para la transcripción de textos antiguos de Bermudo, Cerone y otros respeto la grafía original y sólo modernizo la oscilación entre la " $\mathrm{u}$ " y la " $\mathrm{v}$ ", con valor vocal o consonante según los casos. Modernizo también los signos de puntuación, la acentuación, la separación o la unión de palabras, el uso de las mayúsculas (salvo en casos excepcionales, por el énfasis que se le pueda dar) y disuelvo las abreviaturas. En todos los casos respeto siempre el subrayado de los propios autores, así como sus acotaciones o interpolaciones entre paréntesis cuando las haya. Todo lo que yo añada en la cita para aclarar el sentido o remarcar algún aspecto, va entre claudátur.

${ }^{5}$ Francisco José LEÓN TELLO: Op. cit., p. 520. 
“El canto de órgano se dize canto mensurable y para medirlo se inventó el compás. El compás es un movimiento successivo en el canto, que guía la ygualdad de la medida. Tres maneras hay de compás. Uno se dize compás mayor, o entero, el qual usan los doctos en la música, y es necessario para la hermosura del contrapunto. El segundo se llama compás menor, o compasete, y es la mitad del compás entero. Por facilidad han inventado este compasete los modernos, pero no es aprovado de los varones doctos. El compás tercero es dicho de proporción, en el qual entran tres figuras contra dos en un compás, o de otras muchas maneras."

\section{Y sobre el compás $\mathrm{C}$ en particular puntualiza:}

"Úsase ahora otro tiempo, y es dicho imperfecto, el qual señalan con la figura siguiente: C. [...] En este tiempo vale la máxima ocho compases, el longo quatro, el breve dos, el semibreve uno, dos mínimas en un compás, quatro semínimas en un, compás, ocho corcheas en un compás, y diez y seys semicorcheas en un compás."7

Reproduzco la siguiente tabla que trae Bermudo en la misma página que la cita anterior:

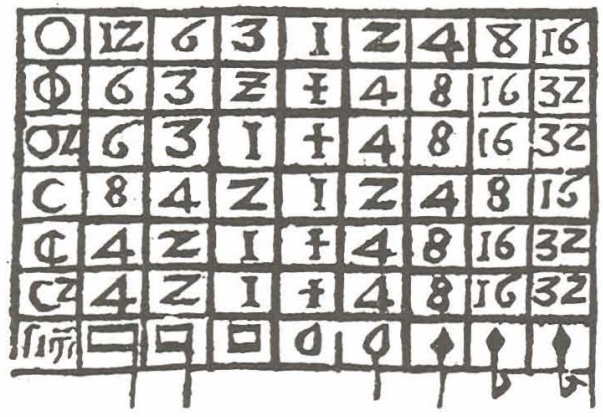

Esta sistematización de Bermudo sobre el compás C va a perdurar en los escritos de tratadistas posteriores, como, por ejemplo, Pedro Cerone, Andrés Lorente y Fray Pablo Nassarre, por citar sólo algunos de los más importantes. ${ }^{8}$

Cerone será el teórico de la música que más voy a utilizar en este trabajo. A pesar de que ha sido vilipendiado sistemáticamente por la historiografía posterior, debido al cariz conservador de su pensamiento y a la prolijidad de

\footnotetext{
${ }^{6}$ Fray Juan BERMUDO: Declaración de Instrumentos musicales, 1555, Kassel und Basel, Bärenreiter Verlag, 1957, (Documenta Musicologica, XI), Faksimile-Nachdruck herausgegeben von Macario Santiago KASTNER, "Libro segundo, De canto de órgano, fol. XXVv. Del compás de canto de órgano, Capítulo XX."

7 Ibídem, "Libro segundo, De canto de órgano, fol. XXVIr. Del tiempo imperfecto, Capítulo XXII."

${ }^{8}$ Cfr. con Francisco José LEÓN TELLO: La teoría española de la música en los siglos XVII y XVIII, Madrid, Consejo Superior de Investigaciones Científicas, Instituto Español de Musicología, 1974.
} 
sus disquisiciones, prefiero acudir al célebre tratadista bergamasco, sobre todo, por la fecha de edición de su Melopeo (1613), ya que se aproxima bastante al período que estudio; y también por la claridad de sus exposiciones. El único problema que existe para hacer una lectura útil e inteligente de su tratado, consiste en saber distinguir el grano de la paja. Cerone sabe lo que quiere decir y lo que pretende con su discurso de carácter didáctico, pero lo envuelve en un ropaje retórico excesivo y lo adorna con continuas citas, simplemente por querer impresionar con su artificiosa erudición. Y esta excusa creo que no debe ser óbice para recurrir a él cuando haga falta. Veamos a continuación su definición del término compás:

“El compás es una medida de tiempo en la música, tomado a intento que las vozes concurran puntualmente en consonancia a un mesmo tiempo; y es la tardança o cantidad de tiempo que ay del golpe que hiere en baxo, a otro siguiente en baxo, effectuado con el abaxar y levantar de la mano. De modo que nos sirve de medida con que medimos toda música prática, particularmente ésta del canto de órgano." ${ }^{\prime 9}$

\section{Más adelante habla de la composición del compás C :}

"Pero el tiempo más usado de todos quantos ay, es el del compassete; y la señal que nos da a entender que cantemos a compasete, o como dizen otros, a compasillo, es el medio círculo en esta forma C. En este tiempo, pues, sin línea atravessada, la máxima vale ocho compases, la longa quatro, la breve dos, la semibreve un compás, y la mínima medio compás, de modo que dos mínimas van en un compás; quatro semínimas, ocho corcheas y deciseys semicorcheas [en un compás, respectivamente]. ${ }^{\prime 10}$

De Andrés Lorente citaré también la sistematización que da del compás binario $\mathrm{C}$ :

"El tiempo menor imperfecto es el que se señala con una Ce, assí: C; llámase vinario, porque van dos figuras de sus menores en un compás, que son dos mínimas; llámase compasillo, porque se canta ligeramente, llevando apresurado el compás."11

Y añade más adelante:

9 Pedro CERONE: El melopeo y maestro. Tractado de musica theorica y pratica, (Bibliotheca Musica Bononiensis, sezione II, n. 25), Bologna, Forni editore, 1969, (Vols. I y II), con una introducción a cargo de F. Alberto GALLO, reimpresión anastática de la edición de Nápoles, Iuan Bautista Gargano y Lucrecio Nucci, impressores, 1613, vol. I, "Lib. VI, Que es del canto métrico, mensural o de órgano. Del compás binario, que es el más usado, Cap. XVIII", p. 495. Vid. otra definición similar en el vol. II, "Lib. XIII, Que es de los fragmentos musicales. Del compás en canto de órgano, Cap. LIII", p. 750.

${ }^{10} \mathrm{Ibídem}$, vol. I, "Lib. VI, Que es del canto métrico, mensural o de órgano. Del tiempo más usado, Cap. XXV", p. 498.

${ }^{11}$ Andrés LORENTE: El porqué de la música, Alcalá de Henares, 1672, "Libro segundo, Arte de canto de órgano. El tiempo menor, ¿por qué tiene diferencia de nombres?, Capítulo XII", p. 154. 
“En el tiempo menor imperfecto, que se señala assí, C [...], la máxima vale ocho compases; el longo vale quatro compases; el breve dos compases; el semibreve, un compás; dos mínimas, un compás; quatro semínimas, un compás; ocho corcheas, un compás; diez y seis semicorcheas, un compás."12

Tras este párrafo Lorente incluye el siguiente ejemplo musical en la p. 156 de su tratado:

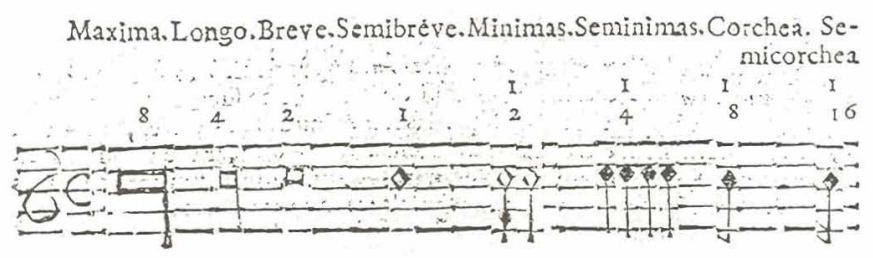

Asímismo, y por último, de Fray Pablo Nassarre:

"Del tiempo imperfecto más usado que tenemos en práctica, llamado compasillo por diminución, o compás menor. [...] Dásele valor de ocho compases a la máxi$m a$, a la longa de quatro, a la breve de dos, a la semibreve de uno, a la mínima de medio, entrando dos en un compás, semínimas quatro, corcheas ocho, y semicorcheas diez y seis; pero el que quisiere usar de las fusas, y semifusas, sepa que entran treinta y dos fusas, y sesenta y quatro semifusas.

"Este tiempo fue inventado de los prácticos modernos [...]. Figúrase este tiempo sólo con un semicírculo sin otra señal alguna."13

Se observa claramente la similitud de planteamiento en los cuatro teóricos, entre cuyos tratados dista más de siglo y medio de diferencia (exactamente ciento sesenta y nueve años). Llama la atención también la contemporaneidad y la utilización general de este compás, así como la constatación de su invención por parte de los músicos prácticos, que buscaban una mayor facilidad y agilidad de ejecución musical con su manejo. Dirá Cerone, al respecto:

"Adviertan que destas figuras [se refiere a las notas mayores] tractaremos conforme a lo que valen cantadas a compasete (que es el tiempo más usado), porque,

${ }^{12}$ Ibídem, "Libro segundo, Arte de canto de órgano. Declaración del número de figuras que ay en el canto de órgano, Capítulo XV", p. 155.

${ }^{13}$ Fr. Pablo NASSARRE: Escuela música según la práctica moderna, Zaragoza, Institución Fernando el Católico, 1980, (Vols. I y II), con un estudio preliminar de Lothar SIEMENS, edición facsímil de la de Zaragoza, Herederos de Diego de Larumbe, 1724. Vol. I, "Lib. III, Capitulo V. En que se explica el tiempo imperfecto, cantado debaxo del compasillo y compás mayor", p. 233. 
quien conforme a este tiempo las supiere cantar, con facilidad las cantará en todos los demás tiempos." ${ }^{14}$

Hasta tal extremo llegaba la prestancia del compás C,

"[...] que no teniendo la obra señal de tiempo, yrá siempre cantada a campasillo [sic] por división binaria." ${ }^{15}$

\section{Aspectos prácticos}

Después de recoger todas estas citas de carácter teórico que hacen referencia a la definición y composición del compás en general, y del binario en particular, será útil observar ahora la concepción práctica que se tenía del compás binario. Recurriré únicamente al testimonio de Cerone:

"[...] El compás binario se divide y parte en dos partes yguales, es, a saver, en dos medios compases, que son sus partes integrales de que se compone; la qual división y partición haze el golpe que hiere en alto. [...] De manera que el compás siempre hiere en baxo, y el medio compás en alto." ${ }^{\prime 16}$

En cada golpe de compás ("baxo" y "alto") entra una mínima (nuestra blanca), tal y como explica Cerone (en otro contexto, pero igualmente válido para mi propósito, $y$, además, porque nos familiariza con la jerga musical de la época):

"Para cantar las mínimas más usadas con facilidad, solamente se requiere advertir una cosa, y es que con cada golpe assí baxo como alto, se canta una mínima. La qual, porque vale medio compás, da a entender que si en ella entraren dando compás, en la figura que se sigue junto a ella entren alçando; y si alçando, dando. De suerte [que] ni mínima se canta sin golpe, ni golpe se hiere sin mínima [...]."17

${ }^{14}$ CERONE: Op. cit., vol. I, "Lib. VI, Que es del canto métrico, mensural o de órgano. El modo que se ha de tener en cantar las figuras a tiempo y conforme sus valores; y primeramente la máxima, la longa y la breve, Cap. XXVII", pp. 498-499.

${ }^{15}$ Ibídem, "Del tiempo músico usado en canto de órgano, Cap. XXIII", p. 497.

${ }^{16}$ Ibidem, vol. II, "Lib. XIII, Que es de los fragmentos musicales. Quantas maneras de compases ay, y de su división, Cap. LIV", p. 751. Cfr. con el vol. I, "Lib. VI, Que es del canto métrico, mensural o de órgano. Del compás binario, que es el más usado, Cap. XVIII", p. 495.

${ }^{17}$ Ibídem, vol. I, "Lib. VI, Que es del canto métrico, mensural o de órgano. Aviso para cantar a tiempo las mínimas, Cap. XXIX", p. 499. 
El siguiente esquema ilustra lo anterior:

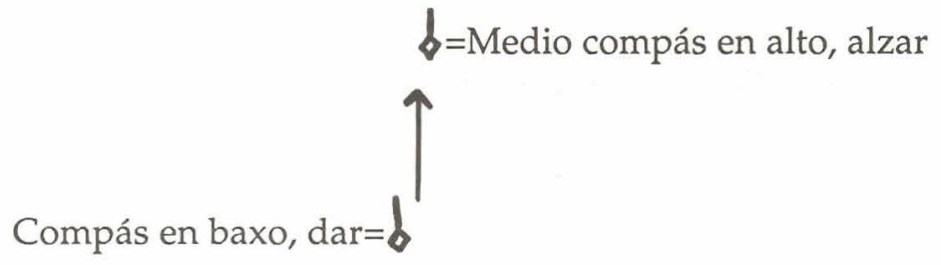

Por otra parte, podemos observar como el tratamiento teórico dado al compás $C$ se asemeja a nuestro actual compás de $4 / 4$, cambiando únicamente el nombre de las notas (semibreve por redonda, mínima por blanca, etc.). En cambio, el tratamiento práctico es diferente, puesto que para ellos era un compás binario, mientras que a la pervivencia que ha llegado hasta nosotros de ese mismo compás, le hemos otorgado una configuración cuaternaria, con el peligro que puede suponer el desconocimiento de esta circunstancia para una interpretación musical correcta.

En realidad, este compás no presenta ningún problema de transcripción a notación moderna, ya que servirá para ello cualquiera de nuestros compases binarios que tenga un 2 como numerador: $2 / 1,2 / 2,2 / 4,2 / 8$, según el valor de las notas que se prefiera aplicar. Sin duda, el compás moderno que más se asimila al antiguo compasillo es el 2/2 (que también se escribe así: $\$$, y, por tradición se denomina "alla breve"). Evidentemente, las transcripciones de esta música con valores reducidos a la mitad, o, incluso, a la cuarta parte, es decir, en compases de $2 / 4$ o de $2 / 8$, no dejan de ser excesivamente prácticas y están del todo alejadas del espíritu de la época, además de ser rechazadas sistemáticamente por los músicos que interpretan esta música según criterios históricos. La justificación que se suele dar a las transcripciones de este tipo, está basada en un argumento tan falaz como el de pretender que su interpretación sea más rápida a causa de la brevedad de los valores, y no tan pesante como con los originales.

\section{EL COMPÁS DE PROPORCIÓN MENOR: CZ}

\section{Aspectos teóricos}

Cerone dedica dos pequeños capítulos de su tratado para describir la manera de llevar el compás binario o ternario en general, y los encabeza con los siguientes títulos: "Del compás binario, que es el más usado" y "Del compás ternario, que es el menos usado"18 (entiéndase aquí por compás ternario el de pro-

${ }^{18}$ Ibídem, vol. I, "Lib. VI, Que es del canto métrico, mensural o de órgano. Del compás binario, que es más usado, Cap. XVIII. [Y] Del compás ternario, que es el menos usado, Cap. XIX", p. 495. 
porción —que para el tratadista italoespañol constaba de dos movimientos: "dar" y "alzar" - y no nuestro ternario común - que para nosotros consta de tres movimientos-; en los aspectos prácticos volveré sobre este tema).

Sin duda, Cerone enfatizaba lo que era la norma común en su ambiente y en su tiempo: el uso mayoritario del compás binario en obras con texto en latín, contraponiéndolo a la menor utilización del compás ternario, que, en lo que se refiere a esas mismas obras, sólo se usaba de manera restringida. ${ }^{19}$

Sin embargo, conforme va avanzando el siglo XVII, en las composiciones con texto en lengua vulgar como letrillas, romances, etc. - en ambientes civiles y cortesanos-, y en los villancicos y romances (en especial la responsión de estos últimos) - en ambientes religiosos-, y dentro del compás ternario en general, escrito de diversas maneras: $\mathrm{CZ}, \mathrm{C} 3, \mathrm{C} 3 / 2, \$ 3$ y $\$ 3 / 2$, se va imponiendo la utilización del compás de proporción menor. ${ }^{20}$ Sobre la masiva utilización de este compás en los villancicos, dice Lorente:

"[...] por quanto de ordinario este tiempo de proporción menor es el que más se exercita en los villancicos y músicas de alegría y regozijo." ${ }^{21}$

Y sobre su uso continuado a lo largo de todo el siglo XVII, que llega, incluso, hasta el XVIII, apunta Nassarre:

"No menos usado que el compasillo, es el tiempo que vulgarmente se llama proporción menor." ${ }^{\prime 2}$

Añadiendo más adelante:

\footnotetext{
${ }^{19} \mathrm{Cfr}$. con los ejemplos que da el propio Cerone de fragmentos de misas y motetes de diversos autores. Ibídem, vol. II, “Lib. XVIII, Que es del valor de las notas en el ternario. Exemplos diversos de proporción, de differentes autores sacados, Cap. IX", pp. 974-975.

${ }^{20}$ Por ejemplo, de las setenta y cinco piezas que forman el Cancionero de Claudio de la Sablonara (colección de composiciones profanas pertenecientes al primer tercio del siglo XVII), cuarenta y siete están escritas en CZ, quince en C y CZ y trece en C. Cfr. con Judith ETZION: El Cancionero de la Sablonara, (Edición crítica), London, Tamesis Books, 1996. Y, por otra parte, los veinticuatro villancicos y romances sacros que se han conservado hasta el presente del maestro Joan Pau Pujol (*1570 - +1626), muestran esa preponderancia del compás ternario de proporción menor sobre el binario: exactamente, quince composiciones están escritas en CZ, siete en C y CZ y solamente dos en C. Cfr. con Mariano LAMBEA CASTRO: Los villancicos de Joan Pau Pujol $\left({ }^{*} 1570\right.$ - +1626). Contribución al estudio del villancico en Cataluña, en el primer tercio del siglo XVII, [tesis doctoral], Barcelona, Universitat Autònoma de Barcelona, 1998.

${ }^{21}$ LORENTE: Op. cit., "Libro segundo, Arte de canto de órgano. Proporción menor, Capítulo XVIII", pp. 165-166.

${ }^{22}$ NASSARRE: Op. cit., vol. I, “Lib. III, Capítulo VI. En que se trata del tiempo de la proporción menor", p. 240.
} 
"[...] siendo el motivo de usarse tanto, y más que el compasillo, quando se compone en lengua vulgar, porque es tiempo acomodado para componer grave, ayroso, alegre, y aun profano." 23

Sin duda, el compás de proporción menor tiene una importancia capital y una significación muy especial en el ámbito de la música vocal española del siglo XVII con textos en lengua vulgar, sobre todo en lo que atañe a las relaciones entre la música y esos textos poéticos. He tenido ocasión de estudiar y analizar estas relaciones en algunos casos concretos y los resultados obtenidos son, en mi opinión, bastante interesantes, aunque ahora no es el momento de detenerse aquí para explicarlos. Lo haré, espero, en un próximo trabajo.

Lo que sí conviene ahora es observar la descripción que hace Cerone del compás ternario en general:

"La segunda manera de compás es ternaria o desigual, que llaman vulgarmente compás de proporción ternaria; y es porque mide tres figuras o su equivalente a cada compás; como si es mayor, tres semibreves; y si es menor, tres mínimas. Y esta proporción ternaria puede ser tripla, midiendo tres figuras contra una; o sexquiáltera, midiendo tres contra dos. ${ }^{24}$

En nuestro caso se trata del compás ternario de proporción menor, que se escribía (en ocasiones, incorrectamente) de varias maneras: C3, \$3, C3/2 en los impresos, y CZ, $\mathbf{C Z}$ (y, a veces, incluso, $\mathrm{Z}^{25}$ ) en los manuscritos, entendiéndose que este signo $\mathbf{Z}$, o un rasgo similar, era una manera rápida de escribir la fracción $3 / 2$.

${ }^{23}$ Ibídem, p. 245.

${ }^{24}$ CERONE: Op. cit., vol. II, "Lib. XIII, Que es de los fragmentos musicales. Quantas maneras de compases ay y de su división, Cap. LIV", p. 750. Cfr. con el vol. I, "Lib. VI, Que es del canto métrico, mensural o de órgano. Del compás ternario, que es el menos usado, Cap. XIX", p. 495.

${ }^{25}$ Tal es el caso del Libro de Tonos Humanos (1655), (Madrid, Biblioteca Nacional, signatura M. 1262), cuyas piezas están escritas en un signo que empieza con la parte superior de un 3 y acaba con un 2. 
Reproduciré a continuación una "tabla" que trae Lorente sobre la manera de escribir este compás, entre otros, y las figuras que entran en ellos ${ }^{26}$ :

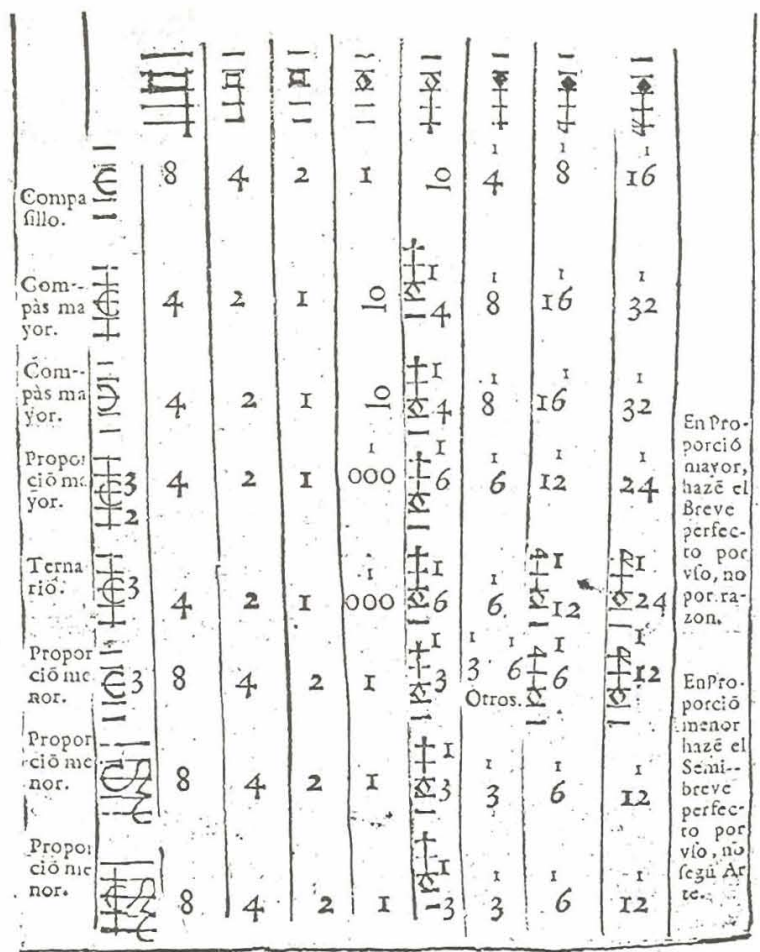

Recogeré ahora el testimonio de Lorente y de Nassarre sobre la manera correcta y académica de anotar este compás; dice Lorente al respecto:

"En el tiempo menor de proporción menor, que [se] señala con una $\mathrm{Ce}$, y un tres guarismo, assí: C3, y por uso con Ce y zeda, assí: CZ. Y también partido el tiempo menor para passar algunas cosas primorosas en la obra a compás mayor, assí: $\$ \mathbf{Z}$. Como se devía señalar este tiempo, era con una $\mathbf{C}$, un dos guarismo y un tres encima de él, de esta manera: $\mathrm{C} 3 / 2 .{ }^{\prime \prime 2} 7$

Por su parte, Nassarre puntualiza que

“Más propia y clara fuera esta señal [se refiere a la de 3/2], si se figurara con el semicírculo, y los dos números, assí: C3/2; [pues,] llevando el semicírculo declara ser

${ }^{26}$ LORENTE: Op. cit., "Libro segundo, Arte de canto de órgano. Tabla del valor de las figuras, Capítulo XXIV", p. 186.

${ }^{27}$ Ibídem, "Libro segundo, Arte de canto de órgano. Proporción menor, Capítulo XVIII", p. 165. 
la breve imperfecta, y que lo sean la longa y máxima también se conoce por la falta de los [sic] señales que las hazen perfectas." 28

Independientemente de su manera de anotarlo, la teoría nos indica que este compás lo ocupaba una semibreve ternaria, es decir, con valor de tres mínimas. He aquí el testimonio de Lorente:

"[...] en este tiempo de proporción menor se cantan tres mínimas en un compás." ${ }^{\prime 29}$

Y el de Nassarre:

"En este tiempo (según comúnmente se usa) son todas las figuras imperfectas, menos la semibreve, que, ora sea por abuso, como quiere Lorente, o por regla, es perfecta [se refiere al orden de medida del «Tiempo»]. Tienen el valor siguiente todas [las notas]: la máxima de ocho compases, la longa de quatro, la breve vale dos, la semibreve uno, tres mínimas entran en un compás, seis semínimas (aunque se pintan como corcheas) y doze corcheas, aunque figuradas como semicorcheas." ${ }^{\prime 30}$

No hay ningún problema en la adjudicación de una tercera parte del compás a cada mínima. El único problema de este compás radica en saber distinguir cuando la semibreve es ternaria, es decir, con equivalencia de tres mínimas, y cuando es binaria, o sea, con equivalencia de dos mínimas. Y este problema no sólo es nuestro a la hora de transcribir, sino que ya lo era para los cantores de la época. De hecho cualquier canto ternario, en el que se hubiera de determinar el carácter binario o ternario de las notas, era dificultoso de interpretar correctamente. Disponemos del testimonio de Cerone sobre este punto:

"[...] considero que los cantos ternarios con perfección, y los binarios a compás mayor, son muy malamente cantados; y no por otra cosa, sino por no tener conoscimiento de la perfección e imperfección de las figuras. ${ }^{\prime \prime 1}$

Por otra parte, la dialéctica «uso» versus «razón» o «arte» no era más que un reflejo del intento de preponderancia de la teoría sobre la realidad prácti$\mathrm{ca}$, o viceversa. Los tratadistas se quejaban de que no se utilizara el antiguo signo mensural de la prolación mayor para la proporción menor, es decir, el semicírculo con un puntillo dentro, ya que, precisamente, ese puntillo era la única señal que otorgaba la perfección a la semibreve, según las normas esta-

\footnotetext{
${ }^{28}$ NASSARRE: Op. cit., vol. I, “Lib. III, Capítulo VI. En que se trata del tiempo de la proporción menor", p. 240.

${ }^{29}$ LORENTE: Op. cit., "Libro segundo, Arte de canto de órgano. Proporción menor, Capítulo XVIII", p. 165.

${ }^{30}$ NASSARRE: Op. cit., vol. I, “Lib. III, Capítulo VI. En que se trata del tiempo de la proporción menor”, p. 240.

${ }^{31}$ CERONE: Op. cit., vol. II, "Lib. XIX, Que es de las proporciones y comp[ases] de diversos tiempos. De las proporciones más necessarias en la música prática, Cap. XVIII", p. 1010.
} 
blecidas a tal efecto. A los tratadistas les irritaba comprobar cómo la proporción menor tomaba prestada la perfección de la semibreve a partir de la prolación mayor, pero sin respetar su signo. Nassarre era el teórico que mostraba argumentos más contundentes ante esta situación:

"Este tiempo, para estar propiamente figurado, avía de ser con un puntillo dentro del semicírculo, en la forma que aquí se ve: $\boldsymbol{\complement}$. Este es el modo con que declara ser la prolación perfecta [=mayor], que es lo mismo que ser ternario el semibreve, valiendo tres mínimas. Pero aviéndo[se] dexado de usar este modo de señal, se figura ordinariamente de ésta: $3 / 2$. No puedo dexar de dezir que es corruptela este modo de figurarle, porque, aunque dan por razón algunos que el tres significa ser el semibreve ternario, y el dos que el breve es binario, no dexa de ser confusa esta figuración e impropia; porque solo el círculo, o semicírculo, es sola la señal [se refiere a la regla u orden de medida denominada «Tiempo»] que haze relación a la breve, según la observación antigua de todos los músicos. ${ }^{\prime 32}$

En la antigua notación mensural, conviene tener siempre presente que no podía haber figura perfecta, sino era bajo los órdenes de medida del «Modo», "Tiempo» o "Prolación»; y esto era norma común para todos los teóricos. Estos órdenes de medida tenían unas señales específicas para cada uno de ellos, que ahora no es preciso recordar aquí. Lo cierto es que la «razón» o el «arte» imponían una señal determinada (para cumplir un precepto, evidentemente), mientras que el «uso» hacía caso omiso de ella y utilizaba otra. Ésta es la razón por la cual los teóricos más sutiles y detallistas hacían esta distinción entre «uso» y «razón» o «arte». Uno de ellos era Cerone:

"[...] muy bien sabemos que, de rigor, ninguna figura cantable puede ser perfeta, no aviendo Modo, Tiempo o Prolación perfeta, aunque está en uso (por carecer de las buenas reglas) que qualquiera figura ternaria, que vale tres de sus menores, pueda ser perfeta." ${ }^{\prime 23}$

Y Lorente, por su parte, añadía sobre el mismo tema:

"En este tiempo de proporción menor es el semibreve perfecto por uso, no por razón." 34

Lo que ocurre es que, a la larga, el «uso» acababa por imponerse. Ya lo intuía Cerone en otro aspecto de la teoría musical, aunque su aplicación aquí es igualmente válida para el caso:

${ }^{32}$ NASSARRE: Op. cit., vol. I, “Lib. III, Capítulo VI. En que se trata del tiempo de la proporción menor", p. 240.

${ }^{33}$ CERONE: Op. cit., vol. II, "Lib. XVII, Que es del Modo, Tiempo y Prolación. Abuso de algunos práticos que, de las señales modales, se sirvieron de indicios proporcionales, Cap. X", p. 953.

${ }^{34}$ LORENTE: Op. cit., "Libro segundo, Arte de canto de órgano. Proporción menor, Capítulo XVIII", p. 166. 
"Más todavía (considerado que el uso es otra ley) [...], sintamos con los pocos [teóricos] y usemos con los muchos [prácticos], aunque es contra razón .[...] Pues sabemos que, a vezes, el uso tiene mayor fuerça que la ley; $y$ es otra ley." ${ }^{35}$

A partir del siglo XVII, y por la propia evolución de la notación musical, el «uso» progresivo de una nueva manera más operativa de escribir el compás irá desplazando paulatinamente la antigua "razón» del sistema mensural. Basta echar una ojeada a la "Tabla del valor de las figuras en todos [los] tiempos, començando por los que se usan, y acabando por los que se han usado"36, que ofrece Lorente en su tratado para percatarse de ello (vid. más arriba la reproducción de dicha "tabla"). Los "tiempos" que se usaban en su época eran cinco (aunque escritos con un total de ocho signos), contra los doce que se habían usado en tiempos pasados. Además de esta prueba documental, existe también la constatación que las mismas obras del siglo XVII nos muestran, pues los compases más usados eran, grosso modo, el compasillo C, el compás mayor $\$$, la proporción menor $\mathbf{C} 3, \mathbf{C Z}, \mathbf{C} 3 / 2$ y Z , la proporción mayor $\$ 3 / 2$ y el ternario $\$ 3 .{ }^{37}$

Sin embargo, el conocimiento de la teoría mensuralista de los siglos XV y XVI era necesario para descifrar las obras antiguas, y por esta razón su estudio era incluido en los tratados posteriores a la época dorada de la polifonía. A pesar de su valor normativo en este sentido, Lorente daba ya por obsoleto - en el último tercio del siglo XVII- el dominio de los antiguos signos de medida en los siguientes términos:

"Aora, antes de començar las breves prácticas de los tiempos antiguos (aunque no usados, muy necessarias para los maestros, para que en ellas adviertan el valor de las figuras y pausas, y sepan qué compás han de hechar, y pertenece a cada tiempo; y no ignorándolas, puedan registrar algunas obras de música antigua, por quanto en ellas ay muchas curiosidades, que por defecto de esta breve inteligencia, muchos, a pesar suyo, las omiten, dexándolas por no entendidas), diremos algunas advertencias $[\ldots] .{ }^{\prime \prime 38}$

${ }^{35}$ CERONE: Op. cit., vol. II, "Lib. XIX, Que es de las proporciones y comp[ases] de diversos tiempos. De como en las proporciones sólo con números no puede aver perfección, alteración ni otros accidentes, Cap. $X I V^{\prime \prime}$, p. 1004.

${ }^{36}$ LORENTE: Op. cit., "Libro segundo, Arte de canto de órgano. Tabla del valor de las figuras en todos tiempos, començando por los que se usan, y acabando por los que se han usado, Capítulo XVIV", pp. 186-187.

${ }^{37}$ Cfr. con otra relación de compases que da Lorente: ibídem, "Libro segundo, Arte de canto de órgano. Exemplo de los tiempos que oy se usan en canto de órgano, donde se verá como han de ser señalados, Capítulo tercero", p. 148.

${ }^{38}$ Ibídem, "Libro segundo, Arte de canto de órgano. Breve explicación de los tiempos que usavan los antiguos en la música, puestos en la tabla antecedente después de los que oy usamos los modernos, Capítulo XXV", p. 188. 
Incluso, Cerone - sesenta años antes que Lorente- ya consideraba como una antigualla el sistema mensural, aunque también mostraba interés por redescubrir músicas del pasado, unido al prurito de saber y de conocer la ciencia antigua. Decía al respecto:

"Y ansí entre las cosas que se nos olvidan de presto, podemos poner las lectiones y reglas del Modo, Tiempo y Prolación.

"Las quales, por averlas los modernos dexado a parte y por no ser tan a menudo exercitadas, muchos que ya en otro tiempo las supieron, agora no se acuerdan más dellas o muy poco, y esto quiçá confusamente. Avemos llegado a tal ser, que muy pocos son los que oy en día sepan enseñar como vayan cantadas las obras compuestas debaxo de las órdenes o reglas del Modo, Tiempo y Prolación; lo qual por otra cosa no acontece, sólo porque aquellas maneras de cantos (como queda dicho) se son dexadas por floxedad y pereza de los práticos, pareciéndoles, que dellas, otra mejor harmonía no se pueda sacar que la ordinaria. Aunque, por otra parte, los scriptores de música nunca dexan (ni dexarán) de dezir algo acerca desto; assi por reputación y honra de la sciencia, y por manifestar sus thesoros y riquezas, como a fin que los compositores y cantores tengan dellas conoscimiento; porque hallando destas particularidades en las composiciones antiguas puedan ser capazes, dando alguna razón dellas, y no quedar en vergüença por cosa de sí poca importancia. ${ }^{39}$

\section{Aspectos prácticos}

Conviene ahora hablar sobre la manera de llevar el compás ternario de proporción menor. En realidad, este compás comprende los dos mismos movimientos que el binario: dar y alzar, pero con la importante salvedad de que, mientras en el binario (pongamos, por caso, el compasillo) entraban dos mínimas al compás - estableciéndose la equivalencia de dos mínimas igual a dos movimientos-, en el ternario de proporción menor entraban tres mínimas al compás - estableciéndose la equivalencia de tres mínimas igual a dos movimientos-. Aun teniendo cada uno de los compases citados idéntica duración temporal, se daba, sin embargo, una sutil diferencia en la configuración de los dos movimientos del dar y alzar. Es mejor dejar que lo explique Cerone:

"Aunque de las tres partes que tiene el compás ternario, cada parte en sí (respecto la una a la otra) es ygual, con todo esso el compás no es ygual, sino desigual; siendo el dar al doblado más largo que el alçar: por quanto se cantan, de las tres, las dos partes en el golpe que hiere en baxo, y una en el alto; assí: un, dos en el dar, tres en el alçar. Digo que la primera es al dar del compás, luego con la misma cantidad o tardança de tiempo se pronuncia la segunda, y al alçar la tercera. Concluyremos, pues, que el compás en número ternario o proporción ternaria (tripla o sexquiálte-

${ }^{39}$ CERONE: Op. cit., vol. II, "Lib. XVII, Que es del Modo, Tiempo y Prolación. A los amigos de antiguallas", p. 936. 
ra que sea) yendo tres figuras en un compás, no se parte en dos partes yguales, como en el compás binario, en dar y alçar; mas, la primera figura es al dar del compás, y luego se pronuncia la segunda, y al alçar la tercera; que es: dos al dar del compás, y una al alçar." 40

Intentaré ilustrar lo anterior con el siguiente esquema:

$$
\phi=\text { Alzar, alto, tres }
$$

Dar, baxo, un $=\varnothing$ dos $=\phi^{\uparrow}$

Nótese que Cerone se refiere a los compases ternarios en general.

Más de medio siglo después, y nuevamente dentro de la controversia entre «uso» y «razón», Lorente se refería a la proporción menor en los siguientes términos (dividiré la cita para incluir mi esquema):

"Advirtiendo que en este tiempo de proporción menor se cantan tres mínimas en un compás; la una es al dar, y las dos al alçar [...] porque sea la cantoría más alegre y ligera $[\ldots]$,

$$
\uparrow \downarrow \delta=\text { Alzar }
$$

esto es según el común uso, que según razón, avía de cantarse una mínima al dar del compás, pronunciando inmediatamente la segunda, y la tercera mínima al alçar." 41

Es posible que la frase de Lorente "porque sea la cantoría más alegre y ligera", se refiera a la especial acentuación que necesita este compás en la segunda de sus mínimas, es decir, la primera que ataca al alzar.

La diferencia entre las posiciones de ambos tratadistas es muy pequeña, ya que Lorente únicamente matiza el pensamiento de Cerone en lo que se refiere a la ligereza del canto según el «uso» de su época, aunque acaba por darle

${ }^{40}$ Ibídem, vol. I, "Lib. VI, Que es del canto métrico, mensural o de órgano. Del compás ternario, que es el menos usado, Cap. XIX", p. 495.

${ }^{41}$ LORENTE: Op. cit., "Libro segundo, Arte de canto de órgano. Proporción menor, Capítulo XVIII", pp. 165-166. 
la «razón» al teórico bergamasco. Por otra parte, parece difícil creer que por cantar la primera mínima al dar del compás, y la segunda y tercera al alzar (al revés de lo que proponía Cerone), haya de ser el canto más alegre. Antes al contrario, pues parece que el compás camine mejor y tenga más aire si se cantan dos mínimas al dar y una al alzar. Sea como fuere, creo que es el texto literario el que manda y el que dispone la conveniencia de llevar este compás de una u otra forma.

Antes de seguir adelante, conviene observar el funcionamiento del compás ternario de proporción mayor. A diferencia de su homónimo de proporción menor en el que entraban tres mínimas, en este mayor entran tres semibreves, siendo una breve ternaria la figura que lo llena. Pero otra diferencia - y muy importante - entre los dos compases radica en la manera de llevarlos, puesto que, independientemente de que entren una o dos figuras al alzar o al dar (ya hemos visto las respectivas posiciones de Cerone y Lorente sobre ese particular en la proporción menor), lo cierto es que la proporción mayor ya no muestra aquella dimensión binaria en dos movimientos de la proporción menor, sino que está concebida como un compás ternario en tres movimientos. $\mathrm{Al}$ menos, eso es lo que se desprende del siguiente párrafo de Lorente, teniendo siempre en cuenta la controversia entre el "común uso» y el «rigor» (divido la cita para incluir mi esquema):

"En el tiempo menor partido de proporción mayor, que [se] señala con una Ce y una vírgula atravesada, un dos guarismo después del tiempo, a la parte baxa, y un tres a la parte alta, desta manera $\$ 3 / 2$. [...] se cantan tres semibreves en cada uno de sus compases, dos al dar y uno al alçar,

$$
\prod_{\operatorname{Dar}=\diamond}^{\Delta \diamond=\text { Alzar }}
$$

esto es según el común uso, que como se deve cantar en rigor es poniendo un semibreve al dar del compás, otro en el intermedio, y otro al alçar." ${ }^{\prime 2}$

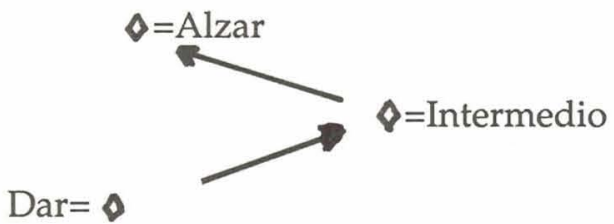

${ }^{42}$ Ibídem, "Libro segundo, Arte de canto de órgano. Proporción mayor, Capítulo XIX", p. 171. 
Y, todavía más, cuando Lorente habla del compás ternario vuelve a incidir en esa configuración ternaria:

"El número ternario se canta, y es en todo como la proporción mayor, y tiene las mismas figuras, pausas y puntillos. Su tiempo es el menor partido, con un tres guarismo, assí: \$3. [...] pronúnciase la primera figura (esto es, el primer semibreve de los tres que van en un compás) al dar; y luego inmediatamente se pronuncia la segunda figura al segundo movimiento del compás; y la tercera figura al alçar del compás; de suerte que en el tiempo de ternario, el compás tiene tres movimientos [...]." ${ }^{\prime 43}$

Resumiendo a grandes rasgos todo lo que se ha apuntado hasta aquí sobre el compás ternario en general, tenemos que la proporción menor es un compás de dos movimientos:

1. dar / 2. alzar.

En cambio, la proporción mayor y el ternario (entendido como proporción tripla) son compases de tres movimientos:

1. dar / 2. un segundo movimiento / 3. alzar).

Esto es lo que dice la teoría, pero ahora cabe preguntarse: ¿todo esto coincide con la realidad musical de los manuscritos conservados? O, lo que es lo mismo, ¿todas estas normas habían sido asimiladas por los músicos prácticos?; ¿se llevaban verdaderamente así esos compases? Es díficil contestar a estas preguntas, sobre todo, si tenemos en cuenta las contradicciones y las incongruencias que presentan muchos manuscritos.

En el arte, la teoría ha desarrollado sus postulados a partir de las obras artísticas, o sea, que ha ido siempre a remolque de los avances, las innovaciones y las aportaciones de la praxis artística. En el caso que nos ocupa, hemos podido observar como, en algunas ocasiones, el «uso» ha intentado imponer su hegemonía ante la «razón», que ha quedado relegada a un segundo plano y ha tenido que conformarse - y empeñarse - en construir un laberinto de normas y leyes para, al menos, salvaguardar un orden lógico y un principio de autoridad. Además, tampoco hay constancia escrita de que muchas de esas normas tuvieran una utilidad puntual; por ejemplo - y volviendo al tema de los compases-, Cerone y Lorente nos ofrecen innumerables variantes de proporciones y compases de todo tipo, caídos por completo en desuso en su época, pero que, sin embargo, están códificados a nivel teórico.

${ }^{43}$ Ibídem, "Libro segundo, Arte de canto de órgano. Ternario, Capítulo XX”, p. 176. 
Por otra parte, en lo que se refiere a la forma de escribir la proporción menor, Lorente dice una cosa muy importante, aunque en relación al compás binario mayor, que creo merece la pena comentar con atención. Retomaré la cita que apunté más arriba sobre la manera de anotar este compás, pero enfatizando lo que en su momento no comenté deliberadamente (ya que en aquel contexto lo consideré superfluo); es el párrafo siguiente, en el que subrayo lo que me interesa:

"En el tiempo menor de proporción menor, que [se] señala con una Ce, y un tres guarismo, assí: C3, y por uso con Ce y zeda, assí: CZ. $\underline{\text { también partido el tiempo }}$ menor para passar algunas cosas primorosas en la obra a compás mayor, assí: $\mathrm{CZ}^{\prime \prime}{ }^{14}$

Sabemos perfectamente que la $C$ indica siempre que la semibreve es la unidad de tiempo, con valor de dos mínimas al compás, y que el signo $\mathbf{Z}$ de la proporción menor señala el valor de tres mínimas al compás. Pero según Lorente, y evidentemente según las intenciones del compositor, también se puede escribir la $\$$, que, al ser compás mayor, señala dos semibreves al compás, y mediante la cual, al parecer, se podrían cantar "algunas cosas primorosas". Prosigo ahora con la cita de Lorente:

"[...] como queda dicho, se suele partir el tiempo menor con una vírgula; y se equivocara este tiempo con el de la proporción mayor, aunque las figuras pudieran quitar la equivocación. ${ }^{\prime \prime 4}$

Del párrafo anterior se puede inferir que, a pesar de que una obra estuviera escrita indistintamente en $\mathbf{C Z}$ o en $\mathbf{C Z}$, lo que realmente importaba era la elección de la unidad de tiempo. En cualquier caso, esta indefinición de escritura seguramente causaría cierta incomodidad a los intérpretes y Cerone ya se quejaba de ello con su prolijidad habitual, pero, por otro lado, necesaria en este caso:

"Muchos se hallan que, con poca consideración, hazen el compás a beneplácito, estando la señal indicial de una composición assí señalada: $\$$, con diminución virgular; la qual medida no será la propria que a la dicha señal conviene, pues dan el compás sobre de una semibreve, haviendo de ser una breve; y este inconveniente cometen para poder cantar con más facilidad. Aunque también podríamos dar otra razón y dezir que cerca de unos deve de ser la ignorancia, y en otros la sobervia, pues ni saben ni quieren ser enseñados, y por esto son causa de mucha confusión [...]. Quisiera yo me dixessen estos tales que dan la medida sobre de una semibreve por compás, después que habrán llegado a una sexquiáltera según la intención del composidor [sic], según su intención dellos, ique proporción será? Ciertamente

${ }^{44}$ Ibídem, "Libro segundo, Arte de canto de órgano. Proporción menor, Capítulo XVIII", p. 165.

${ }^{45}$ Ibídem, p. 165. 
no pueden dezir con verdad que haya de representar sesquiáltera, sino tripla; y esto acontece porque passarán tres semibreves sobre el tiempo de una semibreve, la qual cosa es falsa. Adonde será menester advertir de dar la medida en la breve, y no en la semibreve; y desta manera (conformándose con la intención del autor) passarán en la sexquiáltera tres semibreves en un compás, contra las dos semibreves, o contra una breve, debaxo del dicho semicírculo con raya atravessada. No voy más adelante, por quanto no sé quien me dize al oydo, que ay también muy muchos composidores, los quales señalan la obra con el dicho tiempo, y que después en el progresso della (cantándola conforme la señal) ay unas ina[d]vertencias tan grandes que echan a tierra al cantante por muy diestro que sea; $y$ se hallan cosas que dan a entender que no saben que es lo que puntan." 46

\section{PERFECCIÓN E IMPERFECCIÓN DE LA SEMIBREVE}

Un problema de funcionamiento práctico que presenta el compás de proporción menor es la mala interpretación de la perfección o imperfección de la semibreve. El concepto de perfección e imperfección que, en el mensuralismo anterior, iba íntimamente ligado al orden de medida del «Tiempo» (relación entre la breve y la semibreve), e, incluso, al de la prolación mayor o menor (relación entre la semibreve y la mínima), ahora empieza a aplicarse impropiamente a las proporciones. Esta nueva situación va a generar confusión, prestándose a diversas interpretaciones entre los músicos prácticos de la época, y será a partir de ahora cuando podremos observar cuándo una semibreve puede ser perfecta o imperfecta en los compases de proporción.

Las normas o reglas que otorgaban perfección a la semibreve, y hacían posible que valiera tres mínimas, se hallan cumplidamente detalladas en los tratados que manejo, por lo que no viene al caso incluirlas aquí. Sin embargo, y teniendo a la vista determinados manuscritos musicales de esta época - de los que reproduciré algunos fragmentos (todos escritos en $\mathbf{C Z}$-, conviene precisar lo siguiente (considerando que me voy a referir a la semibreve blanca, es decir, no ennegrecida):

- La semibreve, en proporción menor, vale un compás (o sea, tres mínimas) si después de ella viene una figura que tenga el valor de dos o más mínimas, independientemente del color de esa figura o de si forma parte de una ligadura.

- También valdrá tres mínimas si le sigue una pausa de su mismo valor, o de valor superior. Si después de la semibreve vienen dos pausas de mínima,

${ }^{46}$ CERONE: Op. cit., vol. II, “Lib. XIII, Que es de los fragmentos musicales. Que el cantante es tenido guardar la medida según el indicio del tiempo puesto dal [sic] componedor, y de las composiciones llamadas a notas negras, Cap. LVIII", p. 754. 
éstas tendrán que estar escritas en la misma línea para que aquélla permanezca perfecta. Ilustro las normas anteriores con los siguientes ejemplos musicales, en los que señalo con una $X$ las semibreves que valen un compás (no tengo en cuenta las semibreves sincopadas):
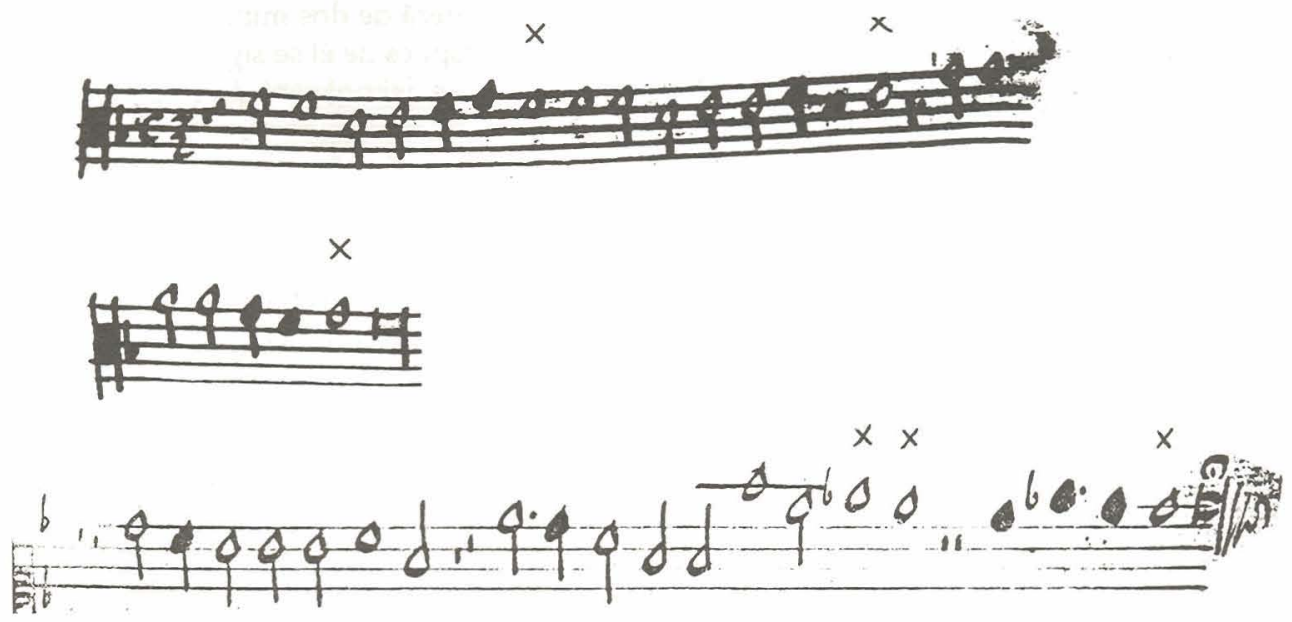

- En caso de que no se cumplan las dos condiciones anteriores, la semibreve también puede ser perfecta siempre y cuando lleve un puntillo de perfección, el cual viene a restituir la perfección perdida por proximidad de figura o pausa menor que ella. Obsérvese en estos ejemplos:

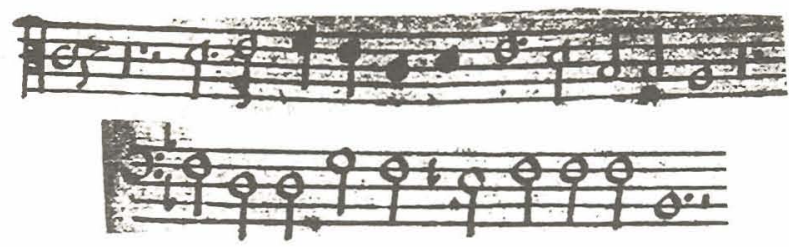

-El requisito indispensable para que la semibreve valga tres mínimas es que ataque al dar del compás, sino sería defecto de escritura.

He aquí la sanción teórica de estas normas en Lorente:

"En este tiempo de proporción menor es el semibreve perfecto por uso, no por razón, esto es, no imperficionándole figura menor que aya después de él; figura me- 
nor es aquella que su valor no llega a dos partes de un compás (esto es al valor de dos mínimas.)

"[...] Para valer el semibreve, en proporción menor, un compás ha de venir al dar y tener después de sí figura mayor, que por lo menos valga dos partes del compás, esto es, que tenga el valor de dos mínimas, o más, o pausa equivalente, o puntillo. No teniendo lo referido, su valor no excederá de dos mínimas; y si viniere dicho semibreve al alzar del compás, aunque después de él se siga figura mayor, o pausa equivalente, no valdrá más de dos mínimas, [si no] será defecto de apuntación. ${ }^{\prime 47}$

En relación a la semibreve ennegrecida:

-Sólo podrá valer tres mínimas si lleva un puntillo de aumentación (mejor que de perfección, aunque el efecto sea idéntico, ya que una semibreve ennegrecida ha perdido su cualidad de perfecta al llenarse de color). En cualquier caso, esta semibreve ennegrecida con puntillo nunca atacará al dar del compás, sino sería defecto de escritura, ya que en este caso concreto no haría falta ennegrecerla y debería mantenerse sin color y sin puntillo (evidentemente, siempre y cuando la siguiera otra semibreve o su pausa, o figura y pausa mayores). En el ejemplo que sigue las semibreves con puntillo valen tres mínimas y las que no lo llevan, dos (obsérvese que las semibreves con puntillo van precedidas de una pausa de mínima la cual posibilita que no ataquen al dar del compás):

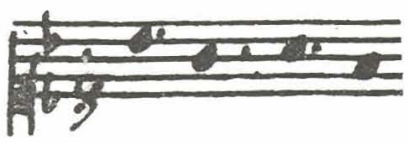

En relación a la breve blanca, es decir, vaciada, no hay ningún problema, ya que siempre es imperfecta, o sea, con valor de dos semibreves (perfectas), puesto que estamos bajo el antiguo signo mensural del tiempo imperfecto C. Véase aquí:

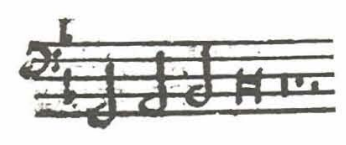

47 LORENTE: Op. cit., "Libro segundo, Arte de canto de órgano. Proporción menor, Capítulo XVIII", p. 166. 
En caso de que el compositor necesite darle el valor de tres semibreves (perfectas), deberá recurrir al puntillo de aumentación. Y si quiere que valga dos semibreves (imperfectas, es decir, cuatro mínimas), tendrá que ennegrecerla. He aquí un ejemplo que contempla ambas opciones:

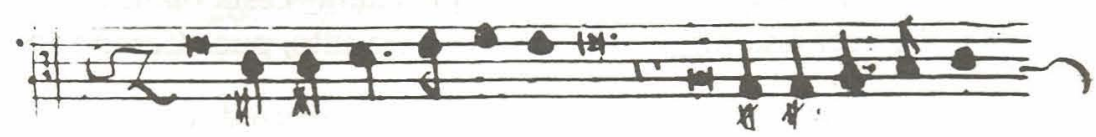

Hay ocasiones, sin embargo, en que la breve blanca va seguida de una mínima, o de su pausa; en estos casos concretos, y para evitar dudas, se la suele distinguir con un puntillo de perfección encima, que la mantiene con el valor de dos semibreves perfectas (dicho puntillo no deja de ser un puntillo de perfección sui generis, puesto que, en rigor, el concepto de perfección siempre está relacionado con el número tres). Sin embargo, dice Lorente al respecto:

"En proporción menor ay otro puntillo, el qual se llama de perfección; éste se pone sobre el breve, quando después de él no ay figura que le perficione; teniendo dicho puntillo vale dos compases [es decir, dos semibreves perfectas]." 48

El siguiente ejemplo que trae Lorente está en la misma página que la cita anterior:

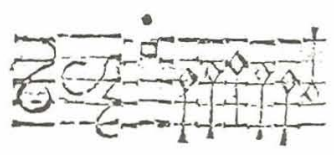

Ahora bien, el inclumpimiento de muchas de las normas anteriores es la tónica habitual en los manuscritos de principios del siglo XVII, excepto en los más pulcros y esmerados. Incluso, conforme avanza el siglo, y en lugar de perfilarse y definirse cada vez más la anotación de este compás de proporción menor, parece, en ocasiones, que su confusión vaya en aumento. Sin embargo, conviene tener en cuenta la preparación y experiencia de cada copista.

\footnotetext{
${ }^{48}$ Ibídem, p. 168.
} 


\section{ENNEGRECIMIENTOS Y HEMIOLIAS}

Es preciso ahora tratar de las figuras ennegrecidas en este compás ternario de proporción menor. En los manuscritos en los que trabajo, y como es usual, son únicamente tres las notas que se ennegrecen: la breve, la semibreve y la mínima, si bien esta última mantiene el mismo valor que cuando está blanca o vaciada. El hecho de ennegrecer una figura no puede ser gratuito, pues Cerone advierte

"[...] que de razón, en los números ternarios, no se han de escurescer las figuras, sino es por fuerça de imperfección [...]."49

Como se sabe, el objetivo de ennegrecer la breve y la semibreve no es otro que el de restarles una tercera parte de su valor; con ello se consigue imperfeccionar a la semibreve, pero no a la breve, porque, como ya hemos visto, esta nota nunca es «perfectamente» ternaria por sí sola en la proporción menor. Vuelvo de nuevo a Cerone, aunque aquí se refiera a la perfección de cualquier nota mayor en general:

“[...] la naturaleza y calidad de las figuras es que cada figura compuesta de número ternario, siendo llena de color, queda imperfeta; es, a saver, queda diminuyda de la cantidad de una tercia parte. ${ }^{\prime \prime 50}$

Obsérvense en este ejemplo las tres semibreves ennegrecidas sin puntillo:

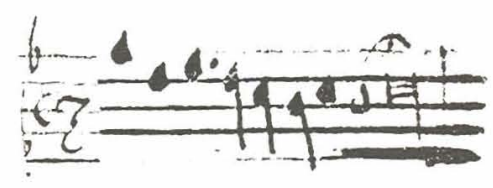

Ahora bien, si, por cualquier circunstancia, el compositor necesitara restituir la perfección perdida por el ennegrecimiento (en el caso de la semibreve que estamos tratando), tendría que añadirle el puntillo de aumentación. Así lo explica Lorente:

"Sepa el curioso [...] que las figuras de nota negra son de proporción sexquiáltera, y que en qualquiera tiempo que se hallaren, sin que le pongan particular, son siempre del número ternario; en las quales figuras no ay perfección, alteración ni división; sólo puede aver en ellas puntillo de augmentación [...].."51

\footnotetext{
${ }^{49}$ CERONE: Op. cit., vol. I, "Lib. VII, Que es de los avisos necess[arios] en canto de órgano. De las notas coloradas y bipartidas, Cap. VI", p. 522.

${ }^{50}$ Ibídem, p. 522.

${ }^{51}$ LORENTE: Op. cit., "Libro segundo, Arte de canto de órgano. Sexquiáltera mayor, Capítulo XXII", p. 181.
} 
Véanse en este ejemplo hasta cuatro semibreves ennegrecidas con puntillo de aumentación:

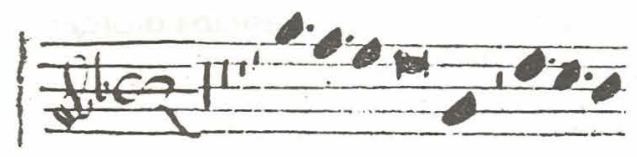

Por otra parte, una nota ennegrecida nunca puede ir sola, sino que tiene que ser completada con otra u otras que llenen uno o varios grupos ternarios (regla u observación que no era precisamente muy respetada por los copistas de la época; antes al contrario, la incoherencia era la norma habitual, excepto, como siempre, en los manuscritos pulcramente trasladados). Sobre la conveniencia de completar los ennegrecimientos Cerone dice lo siguiente:

"Para cuya intelligencia advierto que no se puede poner una sola figura llena, mas conviene le sigua [sic] otra figura negra que cumpla el número ternario (o más números ternarios); y es que la cantidad que pierde una figura mayor por la color, se ha de dar a otra menor." 52

En el ejemplo siguiente cada una de las cuatro semibreves ennegrecidas ha perdido la tercera parte de su valor, o sea, hasta un total de cuatro mínimas. La manera de que esa pérdida quede compensada o regularizada es ennegreciendo cuatro mínimas que estuvieran al principio, en medio o al final del discurso de las cuatro semibreves. En este caso sólo es necesario ennegrecer dos, puesto que con las dos pausas de mínima ya se completa el valor global del diseño (doce mínimas):

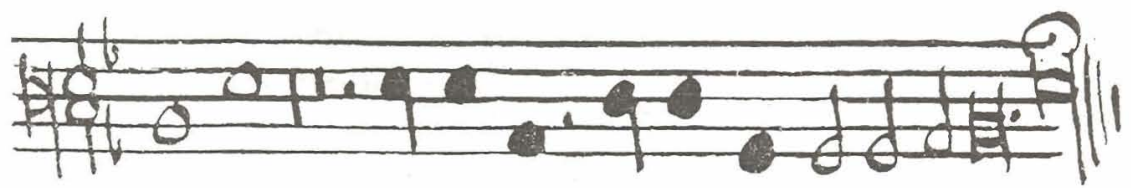

Observemos ahora un ejemplo de incoherencia en los ennegrecimientos, en los cuales no se completan los "números ternarios". En principio existe error del copista, ya sea por omisión o por desconocimiento, puesto que las cuatro mínimas vaciadas tendrían que estar ennegrecidas. Pero es el caso de

${ }^{52}$ CERONE: Op. cit., vol. I, “Lib. VII, Que es de los avisos necess[arios] en canto de órgano. De las notas coloradas y bipartidas, Cap. VI", p. 522 . 
que, hoy por hoy, no tenemos la seguridad absoluta de que el compositor no hubiera querido desatender la teoría con otros fines, tales como la acentuación expresiva del texto literario. Quizá dejó esas dos mínimas sin rellenar para alertar al intérprete acerca del énfasis que deseaba otorgarle a determinada palabra. ${ }^{53}$ Véase el ejemplo con su texto:

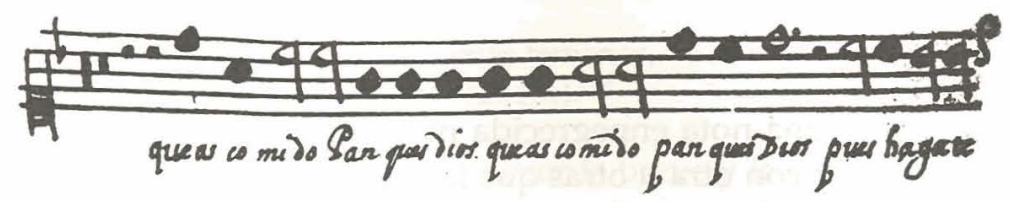

Por otra parte conviente tener presente que la mínima ennegrecida tiene la misma forma y color que la semimínima (o semínima) normal. La explicación que Cerone ofrece en este sentido se refiere aún a aspectos determinados de la prolación, por lo que, una vez más, se puede observar la íntima relación de interpretación existente entre la prolación mayor y la proporción menor:

"[...] que, aunque particularmente en las prolaciones, hallamos semibreves llenas de negrura y mínimas escurecidas, de manera que parecen propriamente semimínimas, no por esso dexan de tener el mesmo valor que tenrían [sic] si fueran vazías y blancas. Las semibreves se hazen negras, porque si fueran blancas, según la regla, estuvieran perfetas; y las mínimas se escurecen, porque los compases ternarios se quedarían sin sus devidos y cumplidos acompañamientos. ${ }^{154}$

La solución para distinguir la mínima ennegrecida de la semimínima normal pasaba por la utilización de otra figura: la corchea blanca (como sustituta de la semimínima). Pero aquí topamos otra vez con el descuido o la falta de rigor de los copistas. Así, los hay que no se servían para nada de la corchea blanca, porque seguramente consideraban que, si iba precedida de una mínima con puntillo de aumentación, no había posibilidad alguna de mala interpretación. En cambio, otros copistas, en el mismo caso que los anteriores, sí la utilizaban con plena consecuencia. Y, por último, algunos la escribían, pero de manera arbitraria, pues, a veces, la equiparaban a la corchea normal, es decir, con la cabeza negra.

\footnotetext{
${ }^{53}$ En cualquier caso falta aún mucho camino por investigar en este aspecto, así como la consulta y confrontación de la mayor cantidad posible de manuscritos de la época. Precisamente una de las líneas de investigación prioritarias en el Departamento de Musicología del CSIC, con el Dr. José Vicente González Valle como gran especialista, es la relación entre música y texto a partir del ritmo musical y de la disposición acentual y expresiva del verso castellano.

${ }^{54}$ CERONE: Op. cit., vol. II, "Lib. XVII, Que es del Modo, Tiempo y Prolación. De las proprias y particulares figuras de la prolación perfeta, Cap. XV", p. 961.
} 
Veamos un ejemplo de corcheas blancas bien escritas (también puede observarse aquí un grupo ternario en el que hay una corchea ennegrecida con valor de una semimínima):

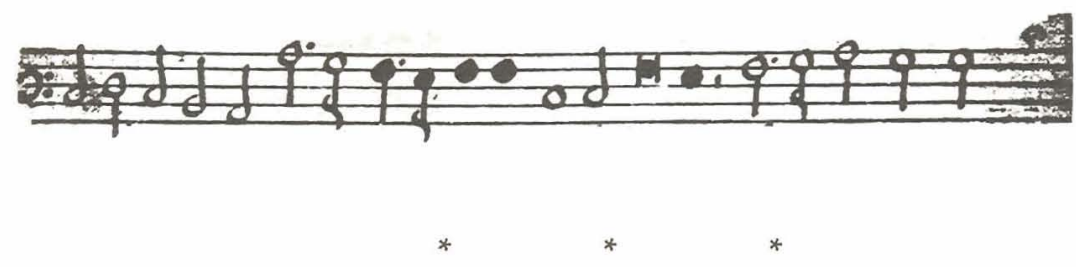

Otro aspecto muy importante de esta notación eran las sucesiones de varias notas todas ennegrecidas. Por ejemplo, si al compositor le interesaba escribir una serie más o menos extensa de semibreves seguidas con valor de dos mínimas cada una, tenía que llenarlas de color, para esquivar así la norma de la perfección. Esto es lo que los teóricos denominaban «hemiolia»; Cerone la definía así:

"Ay después, a vezes, que todas las figuras son negras y llenas, y entonces (como queda dicho) es canto que llaman hemiolia, [o] proporción sexquiáltera; y assí es del número ternario en el compás, en cuyas figuras no hay perfección, alteración ni división." 55

Y, más adelante, la volvía a relacionar con la proporción sexquiáltera, de esta manera:

“[...] assimesmo se acostumbra de apuntar la sexquiáltera y es sin números; escrívese solamente llena de color, llamada comúnmente hemiolia." ${ }^{156}$

Véanse aquí ejemplos de hemiolia con su texto poético:

${ }^{55}$ Ibídem, vol. I, "Lib. VII, Que es de los avisos necess[arios] en canto de órgano. De las notas coloradas y bipartidas, Cap. VI", p. 521 .

${ }^{56} \mathrm{Ibidem}$, vol. II, "Lib. XIX, Que es de las proporciones y comp[ases] de diversos tiempos. Como se deve señalar la tripla, la sexquiáltera y la hemiolia para ser bian apuntada, Cap. XV", p. 1005. 


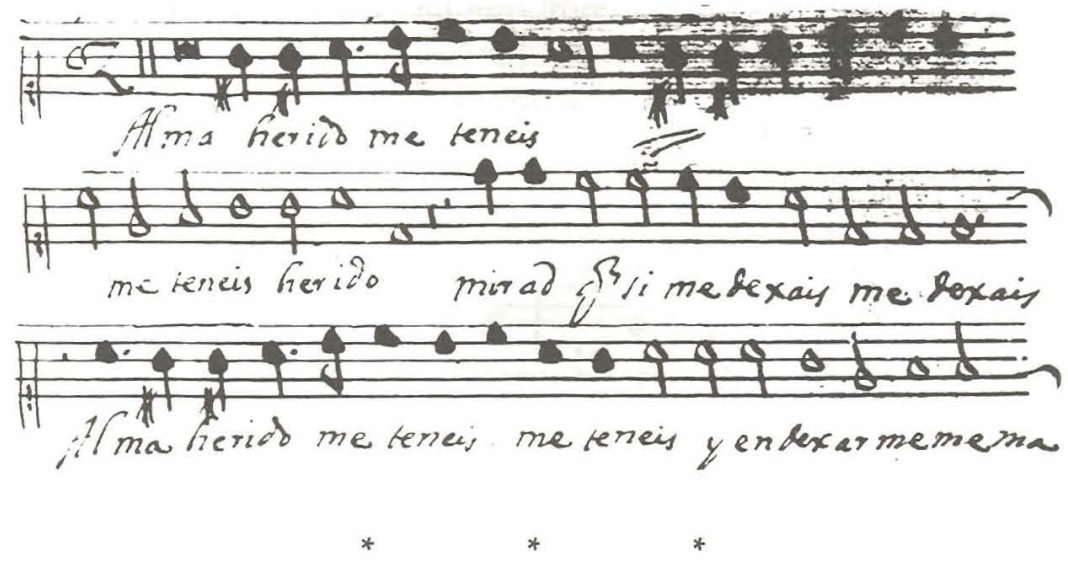

Así como el compasillo no ofrece ningún problema para su transcricpión a notación moderna, no se puede decir lo mismo del compás de proporción menor, el cual exige o muestra un abanico de posibilidades expresivas a tener en cuenta. Posiblemente, el compás moderno que mejor se le pueda asimilar sea nuestro actual 3/2, aunque en mi opinión no acaba de reflejar con la deseada prestancia toda la gama de matices expresivos que la acentuación de las palabras y el ritmo del verso exigen. Sin entrar ahora en cuestiones paleográficos ni en criterios de transcripción a notación moderna - que exigirían un trabajo aparte lo suficientemente amplio y detenido-, en ocasiones se hace necesario cantar en $3 / 2$, en $3 / 1$, e, incluso, en $6 / 2$. En relación al $3 / 1$ recuérdese el interés de Lorente en partir

"el tiempo menor para passar algunas cosas primorosas en la obra a compás mayor, assí: $\$ Z$ Z." ${ }^{157}$

El compás de proporción menor necesita del concurso de los músicos teóricos para su correcta explicación y funcionamiento, pero, en mi opinión, son los músicos prácticos los que tienen la última palabra en lo que respecta a su óptima interpretación, siempre y cuando estén familiarizados con la teoría de la época.

57 LORENTE: Op. cit., "Libro segundo, Arte de canto de órgano. Proporción menor, Capítulo XVIII", p. 165. Cfr. con Luis ROBLEDO: Op. cit., p. 98a, donde remite a diversos ejemplos musicales. 